\title{
Adjustment and health care awareness among youths of
}

\section{Rajkot district}

\author{
Mohit M. Pandya*, Dr. D. J. Bhatt**
}

\begin{abstract}
The purpose of present study was to find out correlation between the youths' adjustment and their health care awareness. The said sample was 240 both males and females in equal numbers was selected through random sampling. Adjustment Inventory \& Health Care Awareness Inventory are tailor-made instruments, having sufficient reliability and validity. For the purpose of analysis, The Karl-Pearans 'r' technique was used. Present study reveals the result that there is significant positive correlation between the youths' Adjustment and their Health Care Awareness. The authors suggest that there is a need to explore the rural and the urban youths' correlation in the line of above study.
\end{abstract}

KEY WORDS: - $\quad$ Adjustment and Health care awareness.

\footnotetext{
* M.A., M.Phil, Department of Psychology, Saurashtra, University, Rajkot, India

**Professor and Head Department of Psychology Saurashtra University Rajkot-360005
} 


\section{INTRODUCTION}

Health care for the youth happiness, health, satisfaction, enjoy peace of mind, physical exercise, regular eating, adequate sleep, etc .should adopt identical. As defined by World Health Organization (WHO 1946), it is a "State of complete physical, mental, and social well being and not merely the absence of disease or infirmity". Young people may also adjust the way work involves adjusting the present study, young adults, and health care awareness are associated with mutual that the studies also made clear. "Adjustment refers to Change in ourselves and our environment to satisfy our needs and to meet with our demands as well as to establish satisfactory relation with others" (Eastward Atwater).

Harlow, Lisa, Weiner, Jennifer, Adams, Jerome, Grebstein, Lawrence. (1995). Psychological adjustment of college student from families of divorce. Positive parent- Child relationships and the smooth relationship of parents are the strongest indicators of the favorable adjustment of children from divorced families to college life. According to an examination of the variable groupings which influenced college adjustment, 'inside family' variables are the strongest predictors of healthy adjustment compared with 'outside family' variables such as negative life events and social support and 'individual' variables which include age at the time of divorce and gender.

R.L. BHARSAKHALE (2013) A study of marriage attitude and adjustment among art and science faculty students by employing a sample of 140 subjects in which 70 subjects were Arts faculty were Arts faculty (35 Male and 35 Female) and 70 subjects were Science faculty (35 Male and 35 Female) with age ranging from 21 to 24 years located From Aurangabad District were selected. The Marriage Attitude scale. This scale was developed and standardized by Pramod Kumar and An Adjustment Inventory (for school and College pupils). This scale was developed and standardized by Dr.Penni Jain. A factorial design was used; since there were two independent variables i.e. Faculty and Gender. A 2x2 factorial design was used to analyzing the data. It was 
found that the Science faculty students have positive marriage attitude from the arts faculty students and Science faculty students have good adjustment than arts faculty students.

Priti Lata and G.L.Yadav (2011) A Study of Youth Problems, Family Relationship \& Certain Psychological Aspects Like Impulsiveness In Relation To 'Academic Achievement of Teen-aged Girls in the Present Era. In the modern era when all the parents desire to see their children, including girls, highly placed, it becomes the topic of at most concern to evaluate their 'Academic Achievement' in relation to familial, social and personal perspective. It is during adolescence that many changes occurs that strongly influence the development of career preferences and aspirations and thus struggle for 'Academic Achievement' Hence, the present study was designed to study the status of 'Family Relationship', ' Youth Problems' and 'Impulsiveness' in 'Teen-aged School' and 'college Girls' and their relationship with Academic Achievement.

Kim, Sooyeon; Brody, Gene H. (2005) Longitudinal Pathways to Psychological Adjustment among Black Youth Living in Single-Parent Households. A 5-wave model linking family and maternal functioning to youth psychological adjustment was tested with 139 single-mother-headed African American families with young adolescents (mean age $=11$ years at recruitment) living in the rural South. Structural equation modeling indicated that an accumulation of family risk factors at Wave 1 was linked with maternal psychological functioning at Wave 2, which forecast competence-promoting parenting practices at Wave 3. These parenting practices indirectly forecast youth externalizing and internalizing behaviors 2 years later at Wave 5, through youth selfregulation at Wave 4. The hypothesized model was retested, controlling for Wave 1 youth externalizing and internalizing behaviors. All paths remained significant, indicating that the model accounted for change in youth psychological adjustment across 4 years. Thus, it becomes clear that the above studies youth adjustment and health care awareness are associated with each other. 


\section{METHOD}

Study method is presented below.

\section{OBJECTIVES:-}

To check correlation between adjustment and health care awareness of Rajkot District youths.

\section{HYPOTHESIS:-}

There is no correlation between adjustment and health care awareness of Rajkot district youths.

\section{SAMPLE:-}

The respondents of the present study 240 young people randomly selected from various areas in Rajkot district. In present research the total sample consisted of 120 male and 120 female Rajkot district were chosen.

\section{TOOLS:-}

\section{REVISED ADJUSTMENT INVENTORY (RAI)}

The revised adjustment scale was made by Pramodakumara (1997). Giving a total of 40 statements. These statements answer 'yes' or 'no' is given in. Its main purpose is to understand the person's general adjustment. In this scale statement no. 33 are positive and others statements are negative. The questionnaire Reliability and validity of this scale was high.

\section{HEALTH CARE AWARENESS INVENTORY}

The health care awareness scale was made by Dr. D. J. Bhatt and Dr. K. N. Jhalodiya (2009). Giving a total of 40 statements. Statements for each 'yes', 'neutral' and 'no' alternatives. Including $1,2,3,5,7,8,9,10,11,12,13,14,16,18,19,20,21,26,29,30,31,34,35,36,40$ Order statements were formative nature. The 4, 6, 15, 17, 22, 23, 24, 25, 27, 28, 32, 33, 37, 38, 39 was the number one form of negative statements. The questionnaire Reliability is 0.89 and Validity is 0.93 established by the author. 


\section{PROCEDURE:-}

In this research two test were administrated individually as well as on young people, which collecting data for the study before attempting the questionnaire the subjects were requested to read the instruction carefully and follow them in true spirits. While the data collection was completed then' ' $r$ ' was used to check correlations.

\section{RESULTS AND DISCUSSION}

Table-1

Correlation calculation between Youth adjustment and youth health care awareness of Rajkot district youths.

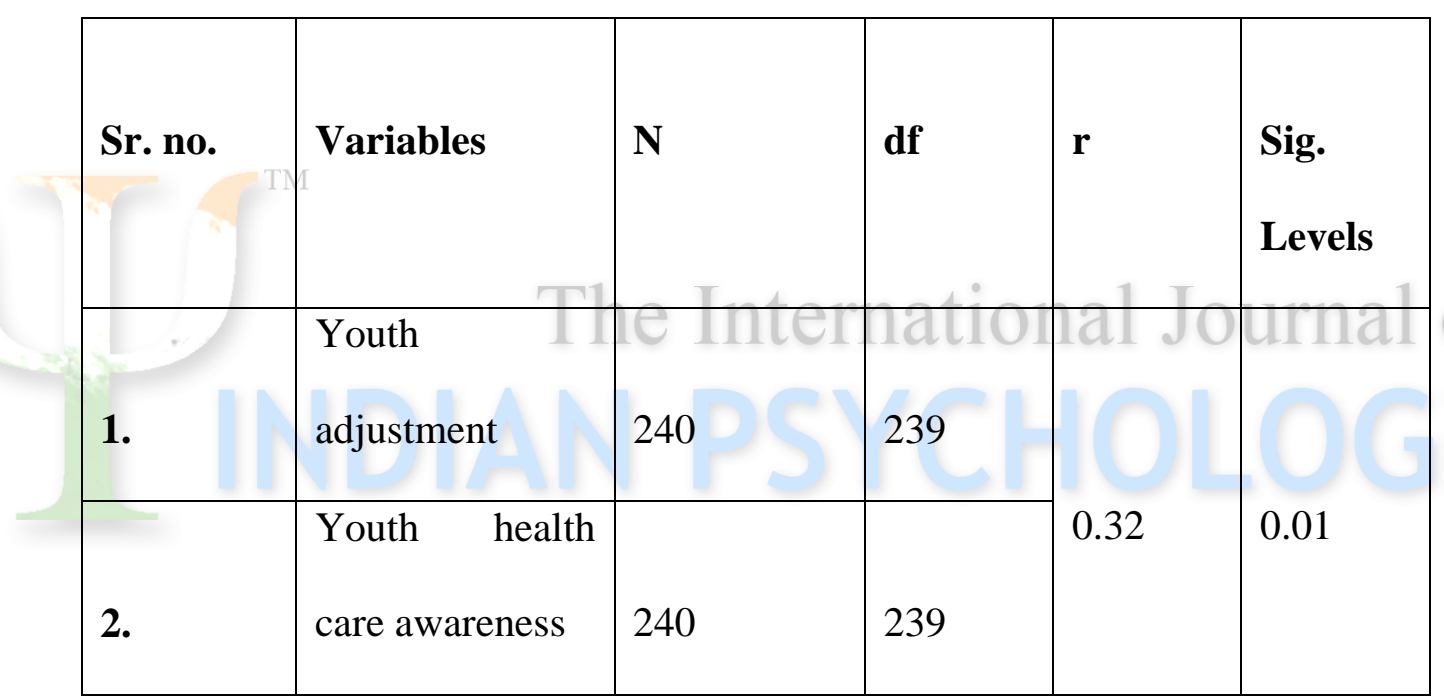

Concluded from the table is that the adjustment and health care awareness a positive correlation of 0.32 between the occurs. Moderately positive correlations that can be called. Around youth health care awareness and adjustment meaningful correlation between the occurs. Hypothesis is therefore to be rejected and the conclusion is that the health care awareness and adjustment are associated with each other. Means that if one increases the other will increase.

\section{CONCLUSION}

The study presented in Rajkot district youth health care awareness and adjustment of which are connected to each other in check. Meaningful result was found. Variable moderately correlation 
was seen between the two. Thus, Youth adjustment and Youth health care awareness is correlated with each other moderately solid. Be the case.

\section{REFERENCES}

1. Antonovsky, A. (1979), Health, stress and coping: New perspectives on mental and physical well being, San Francisco.

2. Atwater, E. (1995). Psychology for living: Adjustment, growth and behavior Today, New Delhi: Prentice Hall.

3. Dr. B. A. Parikh, Individual adaptation of Psychology, Eastwood Atwater. (2003) Psychology of Adjustment, Kim, Sooyeon; Brody, Gene H. Journal of Family Psychology, Vol 19(2), Jun 2005, 305-313. Doi: 10.1037/0893-3200.19.2.305

4. Marks, D.F.Murray, M.Evans, B.Willing, (2001) Health psychology: Theory, Research and practice, New Delhi: Sage Publications.

5. Pritilata and G.L.Yadav, International Referred Research Journal, December, 2011. ISSN0974-2832, RNI-RAJBIL 2009/29954; VoL.III *ISSUE-35

6. R.L.Bharsakhale, Golden Research Thoughts Volume 2, Issue. 12, June. 2013, ISSN:-22315063

7. Tejpreet Kaur Kang \& S.K.Bawa, (1999). Attitude of young adults towards Marriage (Vol. 30, No.1 39- 42) 